Research Article

\title{
Acoustic Emission Response Characteristics of Anthracitic Coal under Uniaxial Compression
}

\author{
Haiyan Wang, ${ }^{1,2}$ Gongda Wang $\left(\mathbb{D},{ }^{1}\right.$ Guojun Zhang $\left(\mathbb{D},{ }^{3}\right.$ Feng Du, ${ }^{4}$ and Ji Ma $\mathbb{D}^{4}$ \\ ${ }^{1}$ School of Civil and Resources Engineering, University of Science and Technology Beijing, Beijing 100083, China \\ ${ }^{2}$ China Coal Research Institute, Beijing 100013, China \\ ${ }^{3}$ State Key Laboratory of Groundwater Protection and Utilization by Coal Mining, China Energy Investment Corporation Ltd, \\ Beijing 102209, China \\ ${ }^{4}$ Beijing Key Laboratory for Precise Mining of Intergrown Energy and Resources, \\ China University of Mining and Technology (Beijing), Beijing 100083, China
}

Correspondence should be addressed to Gongda Wang; wgdcumt@gmail.com and Guojun Zhang; cherish-guojun@hotmail.com

Received 9 August 2020; Revised 3 September 2020; Accepted 15 September 2020; Published 25 September 2020

Academic Editor: Xianjie Hao

Copyright (C) 2020 Haiyan Wang et al. This is an open access article distributed under the Creative Commons Attribution License, which permits unrestricted use, distribution, and reproduction in any medium, provided the original work is properly cited.

\begin{abstract}
The damage evolution of coal is accompanied by the generation of acoustic emission (AE) signal. Through the analysis and research of the $\mathrm{AE}$ response characteristics of coal deformation and failure, it is helpful to reveal the initiation, propagation, and fracture evolution of microcracks in coal. In this work, taking the anthracite coal as research object, the basic mechanical parameters of the coal samples were obtained by ultrasonic tests and uniaxial compression experiments. Meanwhile, the AE response characteristics of coal samples during uniaxial compression were obtained through AE experiments. The results show that when the density is low, the wave velocity of the coal sample decreases with the increase of density. When the density is higher than a certain value, the wave velocity of the coal sample increases with the increase of density. Through the measurement of ultrasonic wave velocity, it is found that there is some nonuniformity and anisotropy in raw coal samples. The ring counts, energy counts, and AE events with time in uniaxial compression process have approximately normal distribution. The AE events are concentrated in the elastic stage and yield stage, and the energy amplitude of AE events is higher in the plastic stage. Compared with the ring counts and energy counts, the AE events have a good positioning function, which can better reflect the evolution of internal cracks of coal samples during uniaxial compression.
\end{abstract}

\section{Introduction}

With the coal resources gradually entering the deep mining stage, under the complex environment of "three-high and one-disturbance," the coal and rock are more prone to fracture and lose stability, leading to more dynamic disasters such as rockburst and coal and gas outburst [1-4]. Moreover, in recent years, the coal-gas compound dynamic disaster, which shows the characteristics of both coal-gas outburst and rockburst, has attracted more and more attentions. It has become increasingly serious and also has become a major disaster affecting China's energy security [5-7]. Coal is a complex heterogeneous material, and there are a lot of microstructures such as cracks and pores inside the coal
$[8,9]$. When these microstructures are stressed, the deformation, stress concentration, and failure will occur, and the stored strain energy will be released in the form of elastic waves, which is the AE phenomenon of the coal and rock under stress [10-12]. The AE signal during the failure of the coal reflects the microscopic destruction of coal and is closely related to the evolution of coal damage. Through the in-depth analysis of the AE signals during the coal damage, the deformation and fracture process of the internal microstructures of coal can be inversed, which is helpful to reveal the evolution law of coal damage and provide references for full understanding of the mechanism, forecasting, and early warning of coal-gas outburst, rockburst, and coal-gas compound dynamic disaster. 
Many scholars at home and abroad have carried out many basic research works on the characteristics of $\mathrm{AE}$ in the process of coal damage. Shkuratnik et al. [13] studied the AE characteristics of coal and rock under uniaxial loading through experiments. By locating the AE source of coal samples under uniaxial compressive stress, Seto et al. [14] pointed out that the AE sources are distributed as a strip along the cracks. Vishal et al. [15] studied the mechanical properties of coal based on the AE method and investigated the influence of $\mathrm{CO}_{2}$ and moisture treatment on the strength of coal. Kong et al. [16-18] introduced the AE critical slowing down theory of coal. They presented that the AE numbers and energy will increase with the increase of gas pressure, while the correlation dimension of $\mathrm{AE}$ parameters shows the tendency of decrement. Du et al. [5] systematically studied the AE characteristics of coal-rock combined bodies. Jiang et al. [19] studied the AE characteristics and energy dissipation of coal under tiered cyclic loading. In Jiang's work, it was indicated that the change of AE of coal under tiered cyclic loading could essentially present the result of coal damage. Song et al. [20] studied the loading-directiondependent anisotropy of coal under uniaxial compression based on AE technology. They also investigated the relationship between cumulative absolute AE energy and anisotropic angle. From the previous research results, the research mainly focused on the evolution characteristics of AE parameters and identification of precursor information of conventional coal and rock damage. In fact, the spatial location of $\mathrm{AE}$ is the most intuitive reflection of the evolution process of material damage, and there are relatively few studies on the spatial evolution law of AE. At present, a lot of early warning researches on $\mathrm{AE}$ to coal and rock dynamic disasters are based on coal-gas outburst and rockburst, and few studies about $\mathrm{AE}$ focus on the early warning of coal-gas compound dynamic disaster. Moreover, the AE theory of coal and rock is not complete. A large number of systematic experimental studies of AE are still needed to reveal the relationship between AE signals and the damage of coal and rock and to analyze the space-time evolution characteristics of AE during the damage of coal and rock, which will provide theoretical guidance for monitoring and early warning of the instability and destruction of coal and rock by acoustic emission.

Based on the analysis above, in this work, taking anthracite coal as the research object, the basic mechanical parameters of the raw coal samples were obtained through ultrasonic testing experiments and uniaxial compression experiments. Meanwhile, the AE response characteristics of raw coal samples in uniaxial compression process were obtained by AE experiment, which provides theoretical guidance for AE monitoring and early warning of failure of coal and rock dynamic disasters.

\section{Coal Samples and the Experimental System}

2.1. Collection and Preparation of Coal Samples. The anthracite coal samples used in the experiments were collected from the 3313 working face of $3 \#$ coal panel in Tang'an coal mine, Jincheng, Shanxi Province. The acquisition point is located at the coal wall, which is $182 \mathrm{~m}$ away from the stoppage line when the working face is pushed forward. The range of $60 \mathrm{~m} \sim 70 \mathrm{~m}$ from the track lane of 3313 working face was selected as the coal block with no obvious crack and good compactness. After the coal was collected, it was wrapped immediately with fresh-keeping film to prevent the weathering of the coal. During the transportation of the coal, several layers of foam film were wrapped to prevent the colliding of the coal blocks and destroy the original joints and cracks to create new fissures. The selected large raw coal was first cut into a $102 \mathrm{~mm} \times 51 \mathrm{~mm} \times 51 \mathrm{~mm}$ cuboid by a rock cutting machine. Then, the six sides of the coal samples were polished by a double-end grinder. Through polishing, the unevenness of the six sides of the coal samples is less than $0.01 \mathrm{~mm}$. Finally, the standard coal samples used for uniaxial compression and $\mathrm{AE}$ test were obtained, as shown in Figure 1.

2.2. Ultrasonic Test. Ultrasonic tests were performed on all standard cube samples, and several samples with the closest wave velocity were selected for mechanical experiments and $\mathrm{AE}$ experiments to ensure that the conclusions drawn in this work are reasonable and reliable. The ZBL-U520 nonmetallic ultrasonic detector was used for the ultrasonic test (Figure 2), and its accuracy of sound time measurement is $\pm 0.05 \mu \mathrm{s}$. Its range of sound time measurement is $0 \sim 600000 \mu \mathrm{s}$. The amplifier bandwidth is $10 \mathrm{kHz} \sim 250 \mathrm{kHz}$ and the receiving sensitivity is less than $30 \mu \mathrm{s}$. First, a vernier caliper was used to measure the length, width, and height of coal sample, and electronic scale was used to measure the mass of the sample. Then, the ZBL-U520 nonmetallic ultrasonic detector was used to measure the wave velocity of ultrasonic through the coal sample, and the average value was measured three times at each position. The detection position is shown in Figure 3. Finally, the basic size, mass, volume, density, and ultrasonic wave velocity of the coal samples can be obtained, as shown in Table 1 .

It can be seen from Table 1 that the density of the eight raw coal samples is 1.44 to $1.78 \mathrm{~g} / \mathrm{cm}^{3}$, with an average of $1.55 \mathrm{~g} / \mathrm{cm}^{3}$. The density of the coal sample varies greatly, and the variance of the density of the sample is 0.02 . The main reason for the density difference of the raw coal samples is that, in addition to the coal matrix, the raw coal sample also contains minerals such as quartz, calcite, and ankerite in different proportions. The ultrasonic wave velocity of the eight raw coal samples is $1.48 \sim 3.25 \mathrm{~km} / \mathrm{s}$, with an average of $2.05 \mathrm{~km} / \mathrm{s}$. The ultrasonic wave velocity changes greatly in the $X$ direction, with a great variance of 0.35 . The fluctuations in the $Y$ and $Z$ directions are relatively close, and the variances are 0.16 and 0.17 , respectively, indicating that the distribution of joint fissures and minerals in the raw coal samples presents obvious directionality. When the density of the raw coal sample is less than the average density of $1.55 \mathrm{~g} /$ $\mathrm{cm}^{3}$, there is an approximately negative correlation between the density and the wave velocity. As the density of raw coal sample increases, the contents of quartz and other minerals gradually increase. Quartz and other minerals are mainly dispersed in raw coal samples, resulting in more interlayers 


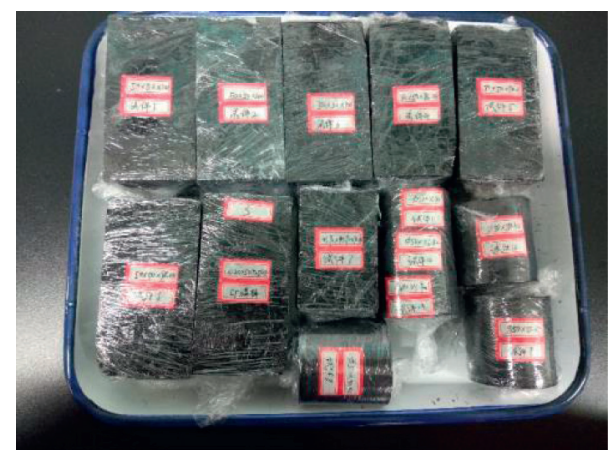

FIgURE 1: The photograph of coal samples.

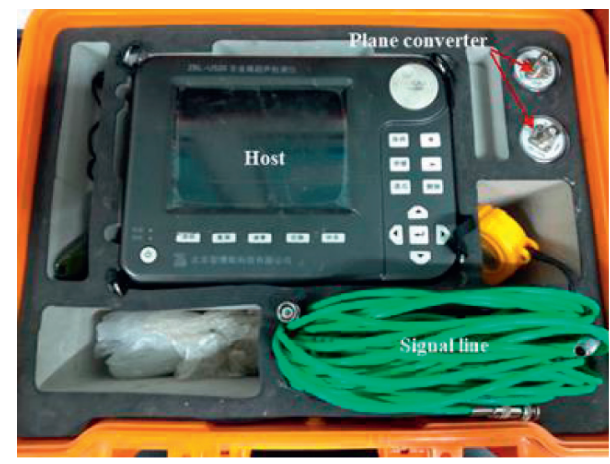

FiguRE 2: ZBL-U520 nonmetal ultrasonic detector.

between coal and quartz, thus reducing the propagation speed of ultrasonic wave in the raw coal samples. When the density is higher than the average density of $1.55 \mathrm{~g} / \mathrm{cm}^{3}$, there is an approximately positive correlation between the density and the wave velocity. As the density of raw coal sample continues to increase, the contents of minerals such as quartz further increase. A relatively concentrated distribution area is formed in the raw coal sample to reduce the number of interlayers, thereby increasing the ultrasonic propagation speed in the raw coal sample, as shown Figure 4.

\subsection{Mechanical Experiment and the AE Experiment System.} The loading system used in the mechanical experiment is the WDW-100E microcomputer-controlled electronic multifunctional testing machine of the Beijing Computing Center. The system can perform uniaxial compression, Brazilian splitting, drawing, bending, shearing, and other experiments of coal and rock. The maximum load is $100 \mathrm{kN}$, and the error is less than $\pm 0.5 \%$, which meets the basic requirements of the uniaxial compression test of the raw coal sample. The AE system is the PCI-2 system of the American Physical Acoustics Corporation (PAC). The system has a built-in 18bit A/D converter, which is more suitable for low-amplitude and low-threshold $(17 \mathrm{~dB})$ settings. It has 4 high-pass and 6 low-pass filters. The frequency range of the system is $1 \mathrm{kHz} 3 \mathrm{MHz}$, and the waveform sampling rate is as high as $10 \mathrm{~m} / \mathrm{s}$. There are eight optional parameter channels on PCI2. Each channel has 16-bit A/D converter, and the speed is $10000 / \mathrm{s}$. The system can realize the parallel operation of multiple FPGA. In addition, the system can also be used as a

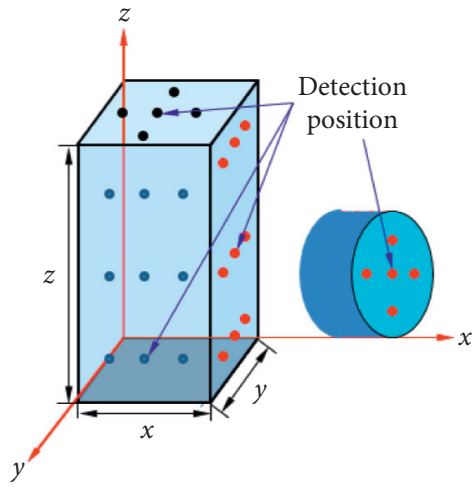

FIGURE 3: Ultrasonic inspection position distribution of the coal sample.

digital signal processing card and provide LabVIEW/C++ driver development program.

First, the BX120-3CA strain gauge was attached to the middle of the two adjacent sides of the raw coal sample. The grid size of the strain gauge is $3 \times 2 \mathrm{~mm}$, the resistance is $119.8 \pm 0.3 \Omega$, and the sensitivity coefficient is $2.08 \pm 1 \%$. Then, a multimeter was used to detect the resistance of the strain gauge. If the resistance range is between 119.5 120.1, the strain gauge is intact; otherwise the strain gauge should be replaced. The paste method of BX120-3CA strain gauge is shown in Figure 5.

After completing the above basic preparations, the noise was tested in the experimental environment. After testing, the threshold of the AE experimental system was fixed at $45 \mathrm{~dB}$. The resonance frequency is $100 \mathrm{kHz} \sim 400 \mathrm{kHz}$. The sampling rate was 1 MSPS, and six sensors were used to collect and localize AE signals. Among them, sensors nos. 1, 2 , and 3 were located at $10 \mathrm{~mm}$ from the upper edge of the raw coal sample, and sensors nos. 4, 5, and 6 were located at $10 \mathrm{~mm}$ from the lower edge of sample, as shown in Figure 6. The six AE sensor channel parameters and three-dimensional positioning settings are shown in Table 2 .

In order to make the probes of the six AE sensors fully contact with the raw coal samples, petroleum jelly was used as the coupling agent to fix the sensor on the surface of the raw coal sample to weaken the attenuation of the AE signal. Meanwhile, the waterproof tape was used for auxiliary fixing. The uniaxial compression loading system for raw coal sample and AE test system are shown in Figure 7.

\section{Experimental Results}

3.1. Uniaxial Compression Test. The WDW-100 E universal testing machine was used to carry out uniaxial compression test, and the basic mechanical parameters of raw coal samples were obtained, such as the whole stress-strain curve, compressive strength, and Poisson's ratio. In the process of uniaxial compression, the loading speed is $0.2 \mathrm{~mm} / \mathrm{min}$, and the stress-strain value of coal sample is continuously recorded until the coal is damaged. Meanwhile, the stress of raw coal sample is obtained by the pressure sensor of universal testing machine, and the strain is obtained by the 
TABLe 1: Preliminary parameters of coal samples.

\begin{tabular}{|c|c|c|c|c|c|c|c|c|c|c|c|}
\hline \multirow[t]{2}{*}{ Number } & \multirow{2}{*}{$\begin{array}{l}\text { Height }(z- \\
\mathrm{mm})\end{array}$} & \multirow{2}{*}{$\begin{array}{l}\text { Length }(x- \\
\mathrm{mm})\end{array}$} & \multirow{2}{*}{$\begin{array}{l}\text { Width }(y- \\
\text { mm })\end{array}$} & \multirow[t]{2}{*}{ Mass (g) } & \multirow{2}{*}{$\begin{array}{l}\text { Volume } \\
\left(\mathrm{cm}^{3}\right)\end{array}$} & \multirow{2}{*}{$\begin{array}{c}\text { Density ( } \mathrm{g} / \\
\left.\mathrm{cm}^{3}\right)\end{array}$} & \multicolumn{3}{|c|}{$\begin{array}{c}\text { Wave velocity } \\
(\mathrm{km} / \mathrm{s})\end{array}$} & \multirow[t]{2}{*}{ Mean } & \multirow[t]{2}{*}{ Variance } \\
\hline & & & & & & & $z$ & $x$ & $y$ & & \\
\hline 0 & 100.20 & 50.40 & 50.40 & 380.60 & 254.52 & 1.50 & 1.74 & 1.91 & 1.74 & 1.80 & 0.0096 \\
\hline 1 & 100.00 & 50.00 & 50.00 & 441.80 & 250.00 & 1.77 & 2.54 & 3.25 & 2.68 & 2.82 & 0.1443 \\
\hline 2 & 100.00 & 50.00 & 50.00 & 379.30 & 250.00 & 1.52 & 1.48 & 1.69 & 1.71 & 1.63 & 0.0166 \\
\hline 3 & 100.00 & 50.00 & 50.00 & 444.70 & 250.00 & 1.78 & 2.54 & 2.81 & 2.65 & 2.67 & 0.0188 \\
\hline 4 & 98.24 & 50.00 & 50.00 & 361.50 & 245.60 & 1.47 & 1.79 & 1.89 & 1.89 & 1.86 & 0.0034 \\
\hline 5 & 98.30 & 50.02 & 50.06 & 354.40 & 246.14 & 1.44 & 1.97 & 1.73 & 1.80 & 1.83 & 0.0152 \\
\hline 6 & 98.44 & 50.02 & 50.06 & 345.90 & 246.49 & 1.40 & 2.22 & 1.94 & 2.18 & 2.11 & 0.0229 \\
\hline 7 & 72.40 & 45.90 & 45.90 & 228.20 & 152.53 & 1.50 & 1.60 & 1.63 & 1.78 & 1.67 & 0.0096 \\
\hline Mean & & & & & & 1.55 & 1.98 & 2.11 & 2.05 & 2.05 & 0.0039 \\
\hline Variance & & & & & & 0.02 & 0.17 & 0.35 & 0.16 & 0.23 & 0.0118 \\
\hline
\end{tabular}

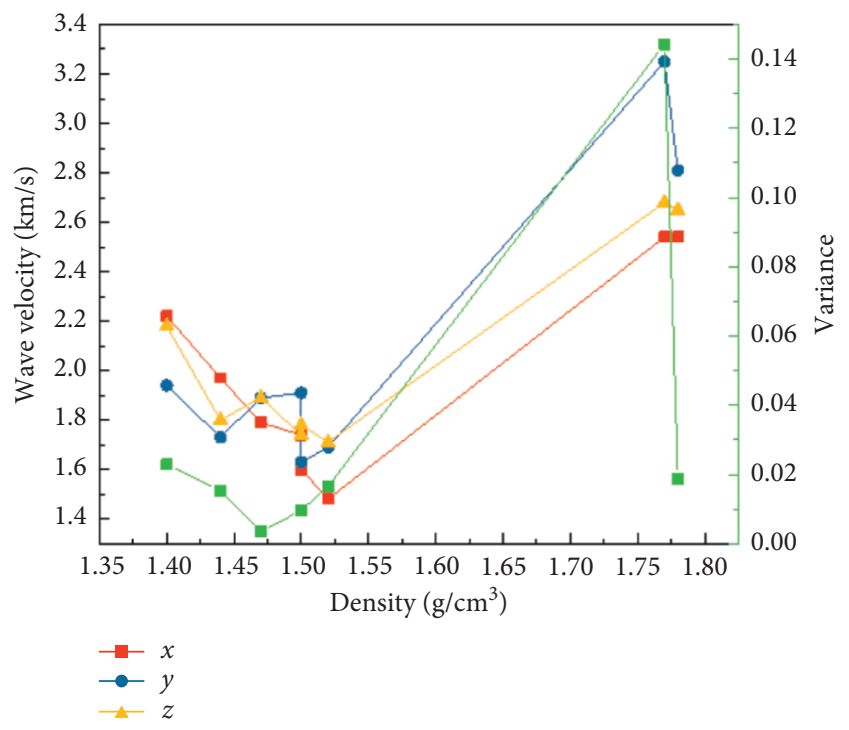

FIGURE 4: Density and ultrasonic wave velocity of coal.

strain instrument connected with the strain gauge of raw coal sample.

Uniaxial compression tests were carried out on samples nos. $0,2,4,5$, and 6 , and the stress-strain curves of raw coal samples were obtained, as shown in Figure 8. The results show that the uniaxial compressive strengths of five samples are $9.31 \mathrm{MPa}, \quad 6.32 \mathrm{MPa}, \quad 7.70 \mathrm{MPa}, \quad 13.92 \mathrm{MPa}$, and $10.06 \mathrm{MPa}$, respectively. The linear elastic moduli of five samples are $1.79 \mathrm{GPa}, 1.29 \mathrm{GPa}, 1.30 \mathrm{GPa}, 2.00 \mathrm{GPa}$, and $1.69 \mathrm{GPa}$, respectively. Poisson's ratios of five samples are $0.34,0.31,0.33,0.30$, and 0.35 , respectively.

The bulk modulus and shear modulus of the coal can be expressed as

$$
\left.\begin{array}{l}
G=\frac{E}{2(1+\mu)} \\
K=\frac{E}{3(1-2 \mu)}
\end{array}\right\},
$$

where $G$ is the shear modulus and $K$ is the bulk modulus. $E$ is Young's modulus and $\mu$ is Poisson's ratio.
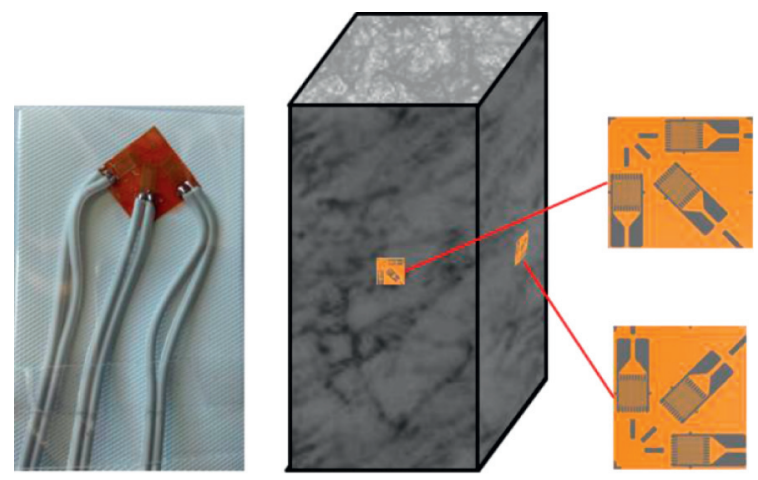

FIgURE 5: BX120-3CA strain gauge and its paste method.

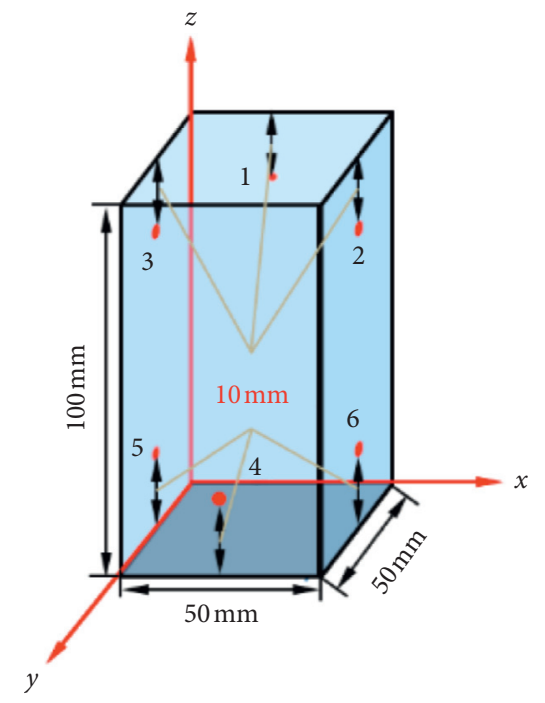

FIgURE 6: AE sensor spatial distribution.

According to equation (1), the relationship between bulk modulus, shear modulus, and Poisson's ratio can be obtained as

$$
\mu=\frac{3 K-2 G}{6 K+2 G} \text {. }
$$

The Poisson's ratio distribution of coal is mainly in the range of $0-0.5$. By further sorting out equation (2), the following formula can be obtained: 
TABLE 2: AE channel and positioning settings.

\begin{tabular}{lcccccc}
\hline Number & PDT $(\mu \mathrm{s})$ & HDT $(\mu \mathrm{s})$ & HLT $(\mu \mathrm{s})$ & Definition value $(\mathrm{mm})$ & Locking value $(\mathrm{mm})$ & Positioning length value $(\mathrm{mm})$ \\
\hline $1 \sim 4$ & 50 & 150 & 200 & 78.0000 & 156.0000 & 7.8000 \\
$5 \sim 6$ & 200 & 800 & 1000 & & & \\
\hline
\end{tabular}

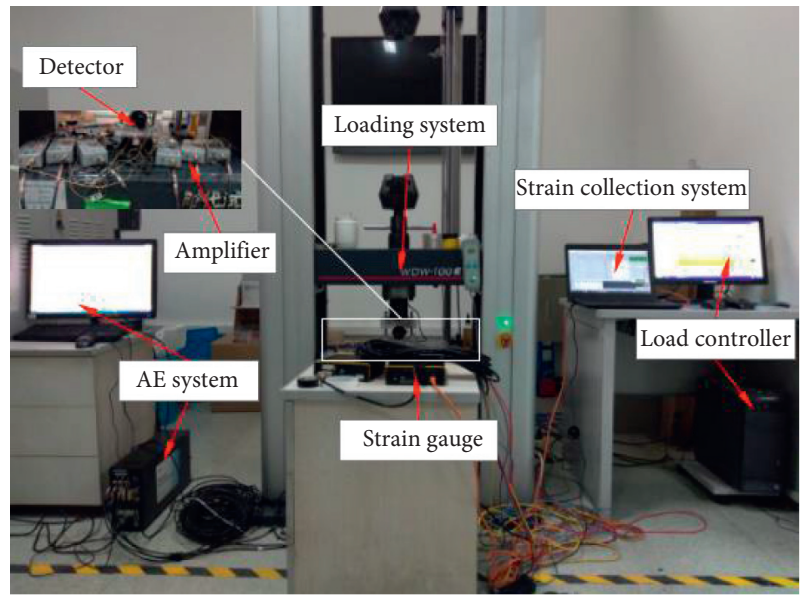

FIgURE 7: WDW-100E universal testing machine and AE system.

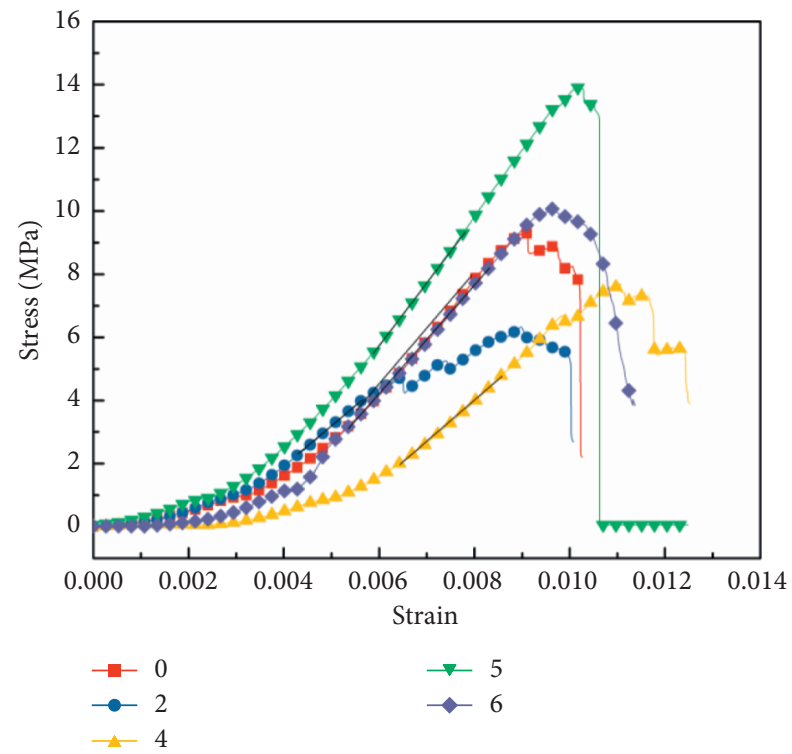

FIGURE 8: Stress-strain relationship of coal samples under uniaxial compression.

$$
\eta=\frac{3(1-2 \mu)}{2(1+\mu)}
$$

where $\eta$ is the ratio of shear modulus $G$ to bulk modulus $K$ $(\eta=(g / k)) . \mu$ is Poisson's ratio. Given that the range of Poisson's ratio is $0-0.5$, the value range of $\eta$ is $0-1.5$.

Poisson's ratio of coal material is related not only to $G$ and $K$ but also to internal friction angle. Sun [21] deduced a shear failure strength criterion of continuous medium rock mass based on Mohr-Coulomb strength criterion:

$$
\mu=\frac{1}{2}(1-\sin \varphi)
$$

In addition, Zhang [22] studied Poisson's ratio and internal friction angle in depth and presented that there is $\mu \leq \tan \varphi(1-\sin \varphi)$ in brittle failure of rock. Therefore, it can be seen that the values of $\mu$ and $\varphi$ directly affect the failure type of materials.

According to equations (1)-(4), the basic relationship between Poisson's ratio and internal friction angle can be obtained, as shown in Figure 9.

If the yield process of the material satisfies the MohrCoulomb criterion, the relationship between the uniaxial compressive strength and the cohesion and the friction angle of the material is

$$
\sigma_{u}=\frac{2 c \cos \varphi}{1-\sin \varphi}
$$

where $\sigma_{u}$ is the uniaxial compressive strength, MPa. $c$ is the cohesion, MPa.

Finally, the basic mechanical parameters of five coal samples can be calculated by uniaxial compression tests, as shown in Table 3.

It is shown that although the selected raw coal samples are taken from the same block coal and the wave velocity is relatively consistent, the mechanical properties are still different, which further proves the heterogeneity of coal. The enlightenment to us is that, in order to reduce the experimental error, it is necessary to select more coal samples for repeated experiments on the basis of economy and convenience.

3.2. AE Response Characteristics. The AE tests and uniaxial compression tests are carried out at the same time. Due to the failure of the AE instrument, we have not collected all the AE signals in the process of uniaxial compression tests. Only the AE response signals of raw coal samples nos. $0,2,4$, and 5 were collected. Therefore, the AE response characteristics of raw coal samples nos. $0,2,4$, and 5 were only analyzed in this work.

3.2.1. Ring Count Analysis of AE Signal. The ring count of $\mathrm{AE}$ signal refers to the number of times that the AE signal exceeds the set threshold, which can roughly reflect the intensity and frequency of the signal. The relationship between AE ring count, axial stress, and time is shown in Figure 10.

It can be seen from Figure 10 that the ring count with time in uniaxial compression process has approximately normal distribution. The AE ring count is mainly concentrated in the linear elastic stage and plastic deformation stage of raw coal sample, and the maximum value of ring count appears in the plastic deformation stage of raw coal sample. The change of cumulative ring count value is in line with the 


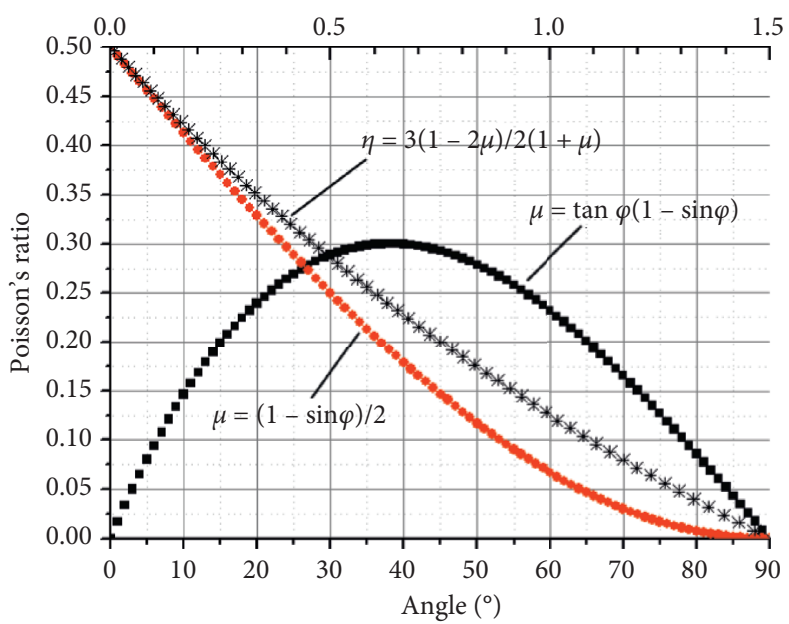

Figure 9: Relationship between Poisson's ratio and the friction angle.

TABLE 3: Mechanical parameters obtained from the experiment.

\begin{tabular}{lccccccc}
\hline Number & $\begin{array}{c}\text { Compressive strength } \\
(\mathrm{MPa})\end{array}$ & $\begin{array}{c}\text { Linear elastic } \\
\text { modulus }(\mathrm{GPa})\end{array}$ & $\begin{array}{c}\text { Poisson's } \\
\text { ratio }\end{array}$ & $\begin{array}{c}\text { Internal friction } \\
\text { angle }\left(^{\circ}\right)\end{array}$ & $\begin{array}{c}\text { Bulk modulus } \\
(\mathrm{GPa})\end{array}$ & $\begin{array}{c}\text { Shear modulus } \\
(\mathrm{GPa})\end{array}$ & $\begin{array}{c}\text { Cohesion } \\
(\mathrm{MPa})\end{array}$ \\
\hline 0 & 9.31 & 1.79 & 0.34 & 18.65 & 1.86 & 0.67 & 3.42 \\
2 & 6.32 & 1.29 & 0.31 & 21.80 & 1.16 & 0.49 & 2.27 \\
4 & 7.70 & 1.30 & 0.33 & 20.12 & 1.26 & 0.49 & 2.61 \\
5 & 13.92 & 2.00 & 0.30 & 23.66 & 1.66 & 0.77 & 4.86 \\
6 & 10.06 & 1.69 & 0.35 & 17.39 & 1.88 & 0.63 & 3.29 \\
Average & 9.46 & 1.61 & 0.33 & 20.32 & 1.57 & 0.61 & 3.29 \\
\hline
\end{tabular}

Note. Since Poisson's ratio of raw coal samples is greater than or equal to 0.3 , the calculation of friction angle is based on formula (4).

change law of axial stress of raw coal sample during uniaxial compression. According to the whole stress-strain zoning of coal, the stress-strain relationship is related to the compaction, formation, development, and expansion of internal cracks, and the corresponding pulse elastic wave is formed during the compaction, formation, development, and expansion of cracks. By analyzing the change characteristics of ring count, the formation, development, and expansion characteristics of the internal cracks in raw coal samples can be obtained.

3.2.2. Energy Characteristic Analysis of AE Signal. The energy of AE signal is the reflection of relative energy or relative intensity in $\mathrm{AE}$ events and it is less affected by threshold, operating frequency, and propagation characteristics. The relationship between the AE energy count and the axial stress and the time of raw coal sample during uniaxial compression is shown in Figure 11.

It can be seen from Figure 11 that the energy count with time during uniaxial compression is approximate to normal distribution. The AE energy count mainly concentrates in the linear elastic stage and plastic deformation stage of raw coal sample, and the maximum value of ring count appears in the plastic deformation stage of raw coal sample. The energy count and its cumulative value are close to the axial stress change in the uniaxial compression process. Therefore, the energy and ring count both can reflect the formation, development, and expansion of the cracks of the raw coal sample during uniaxial compression.

3.2.3. Event Analysis of AE Signal. The AE events refer to the local changes in the interior of materials, which can reflect the total amount and frequency of AE. They are usually composed of one or more impact events, which are mainly used to evaluate the activity and concentration of $\mathrm{AE}$ sources. The relationship between $\mathrm{AE}$ events and axial stress and time of raw coal sample during uniaxial compression is shown in Figure 12.

It can be seen from Figure 12 that the AE events with time during uniaxial compression are still approximate to normal distribution. The AE events are mainly concentrated in the linear elastic stage and plastic deformation stage of raw coal samples, and the maximum value of $\mathrm{AE}$ events occurs in the plastic deformation stage of raw coal samples. The change of cumulative AE events is also close to the stress variation law of raw coal samples during uniaxial compression. The AE events and their cumulative values are still close to the ring counts and their cumulative values. Compared with the ring count and energy count, AE events can better reflect the formation, development, and expansion of cracks of the raw coal sample during uniaxial compression.

In order to more intuitively show the evolution law of $\mathrm{AE}$ events with time and space under uniaxial loading of raw 


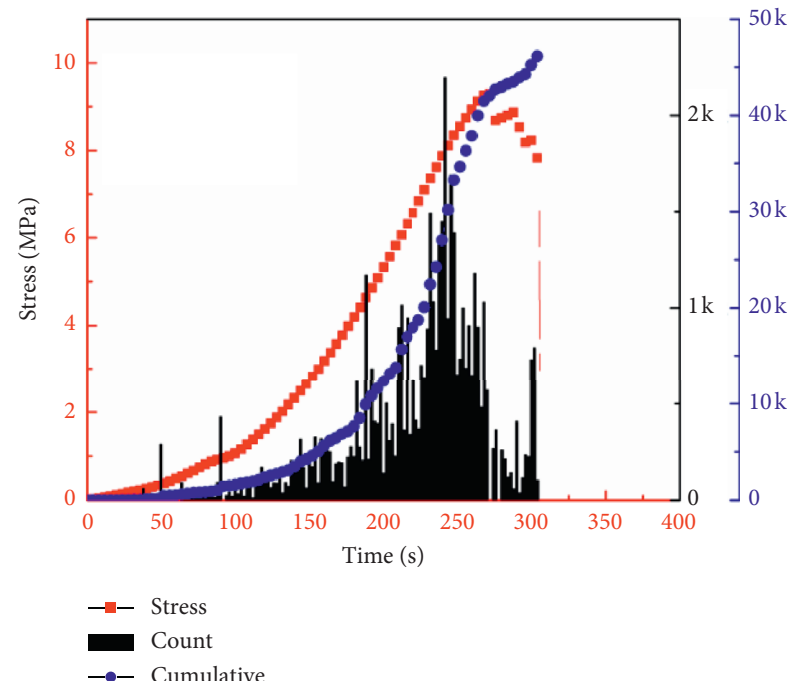

(a)

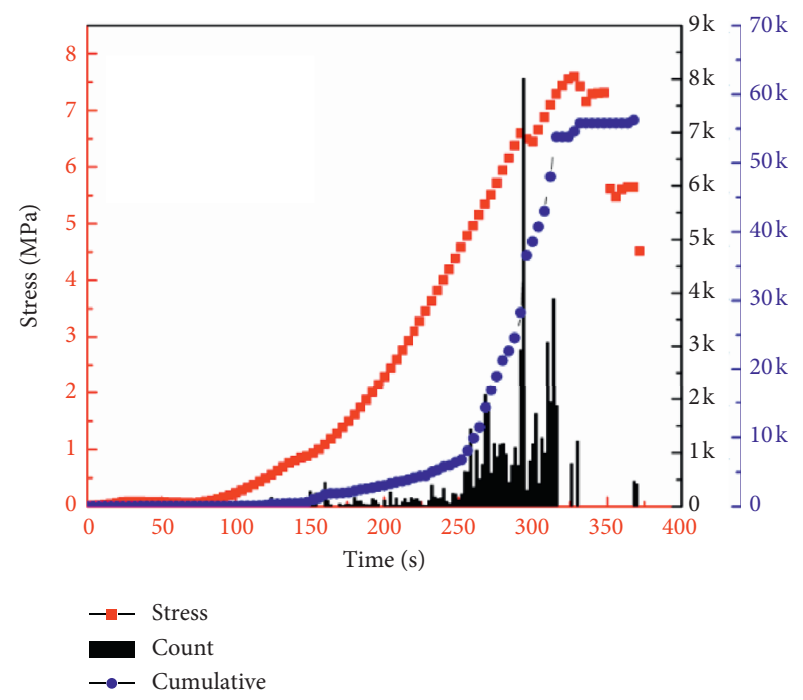

(c)

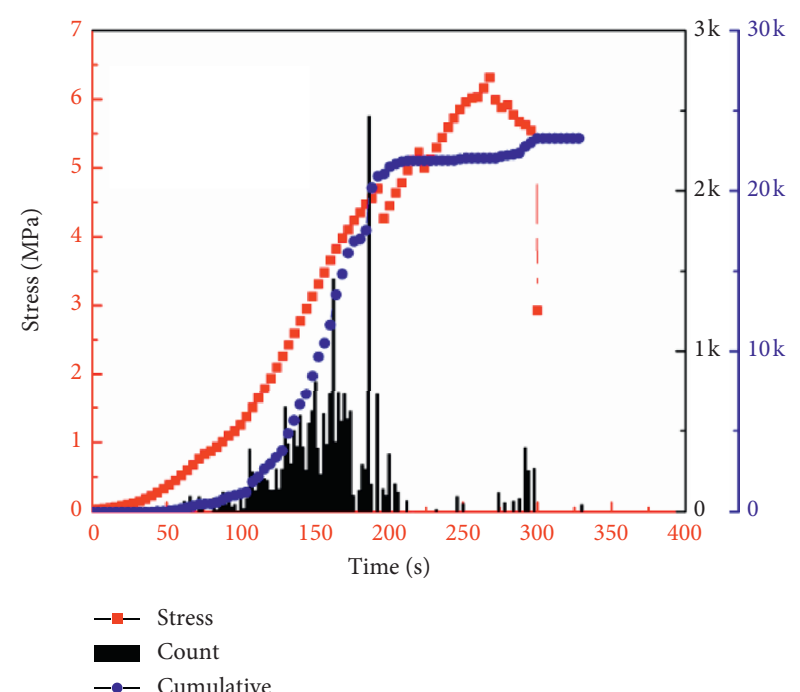

(b)

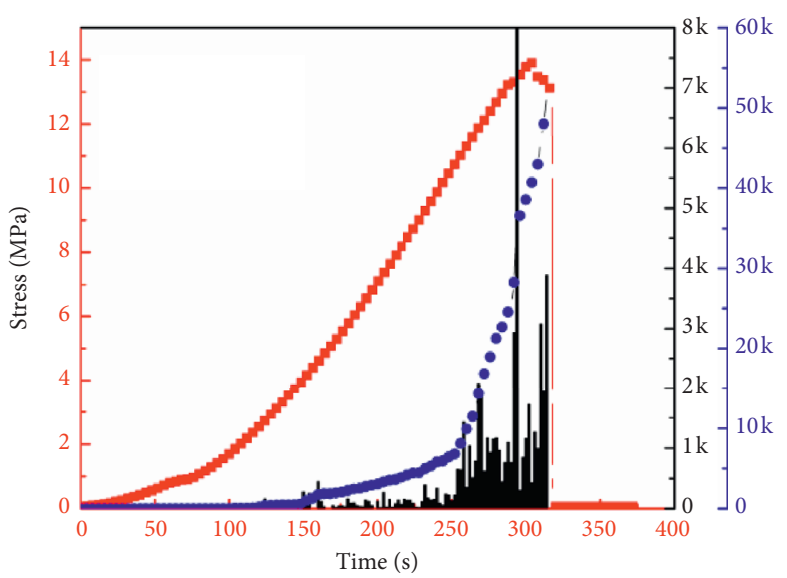

$-\square-$ Stress
- Count
$-\bullet$ Cumulative

FIgURE 10: Relationship between AE ring count, stress, and time (“count" represents AE ring count and "cumulative" represents AE cumulative ring count). (a) Coal sample no. 0. (b) Coal sample no. 2. (c) Coal sample no. 4. (d) Coal sample no. 5.

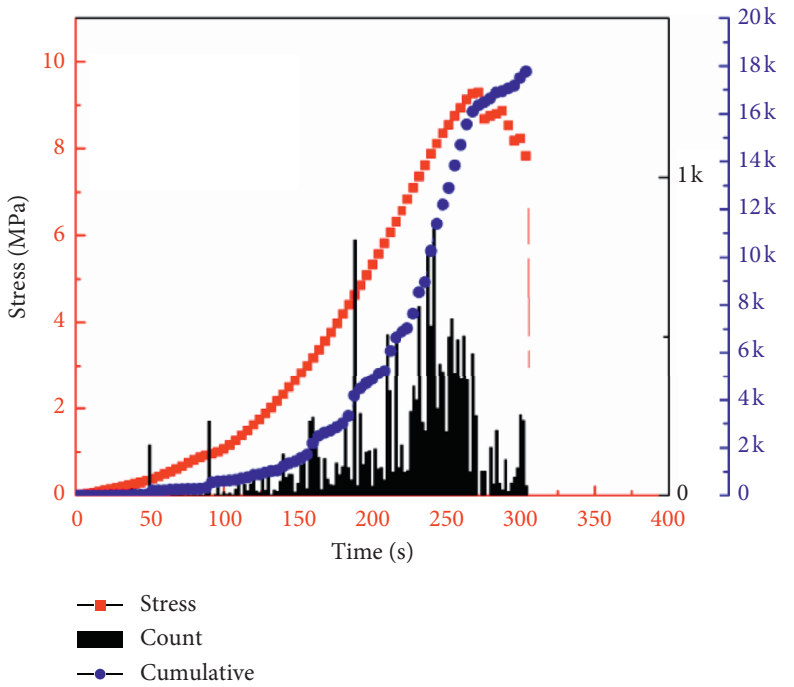

(a)

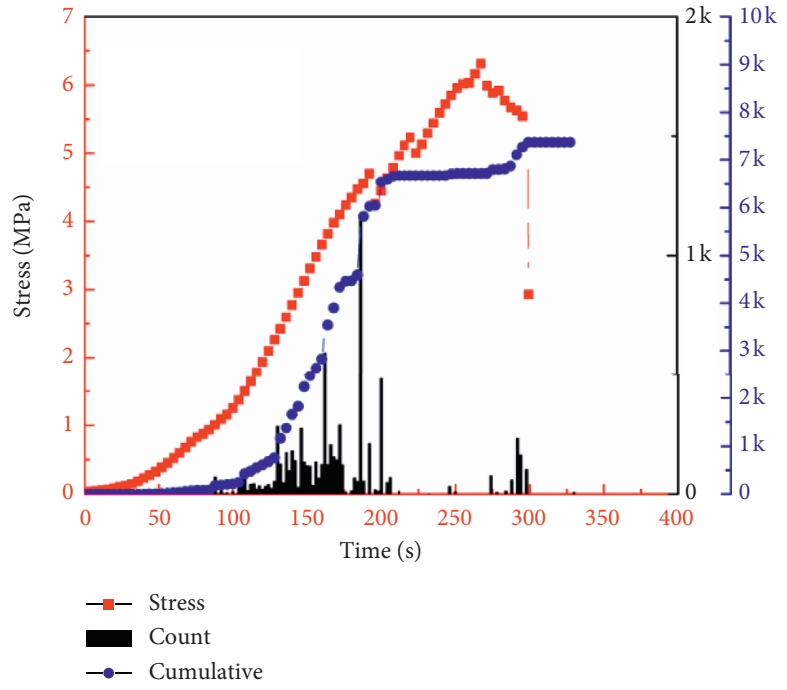

(b)

Figure 11: Continued. 


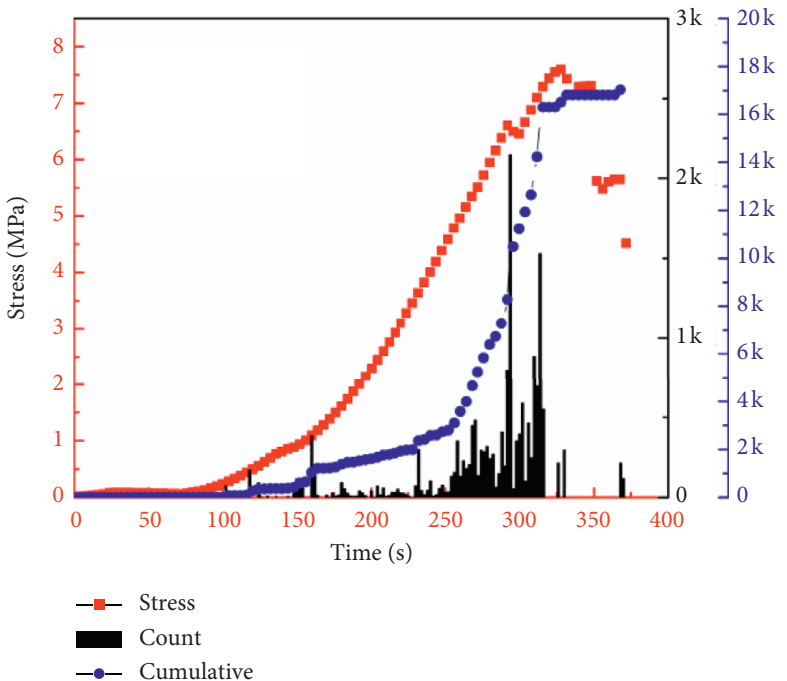

(c)

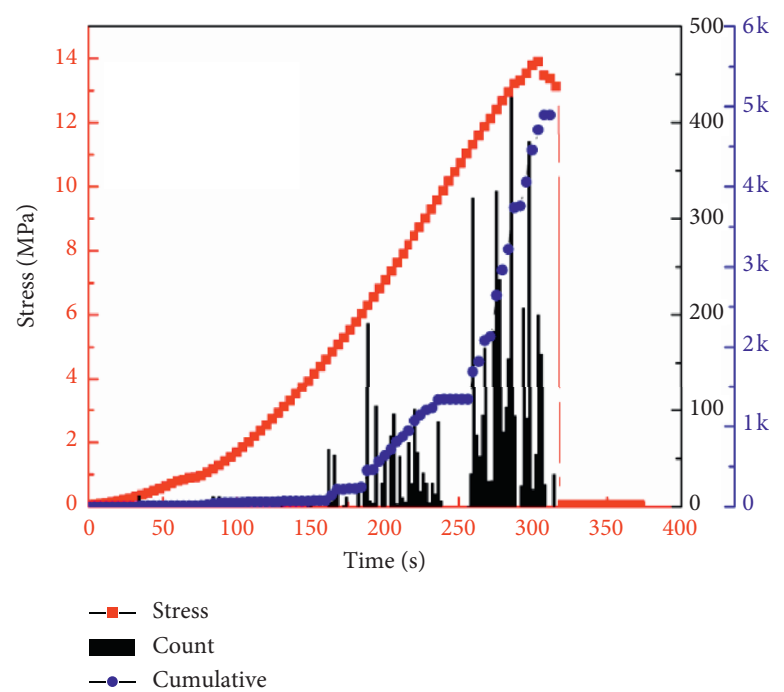

(d)

Figure 11: Relationship between AE energy, stress, and time ("count" represents AE energy count and "cumulative" represents AE cumulative energy count). (a) Coal sample no. 0. (b) Coal sample no. 2. (c) Coal sample no. 4. (d) Coal sample no. 5.

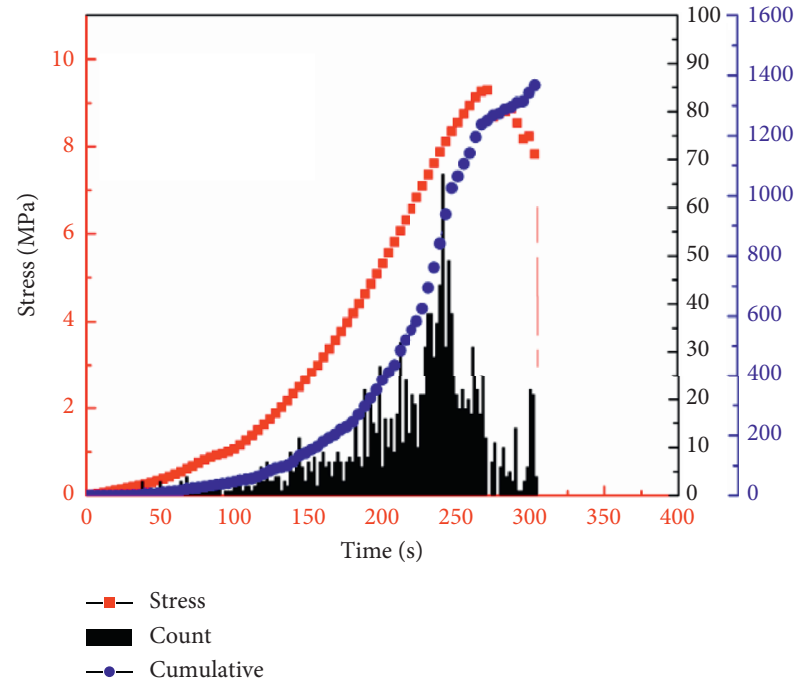

(a)

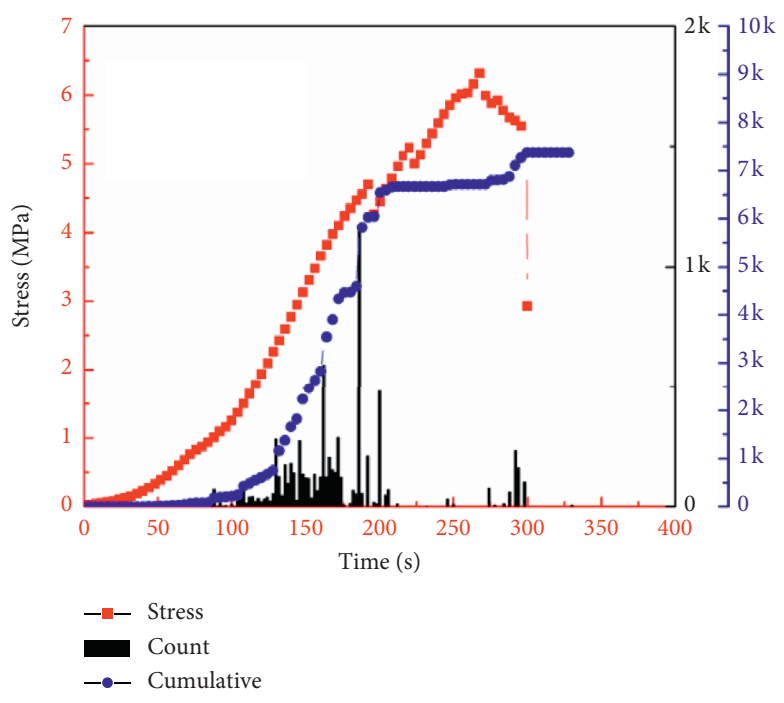

(b)

Figure 12: Continued. 


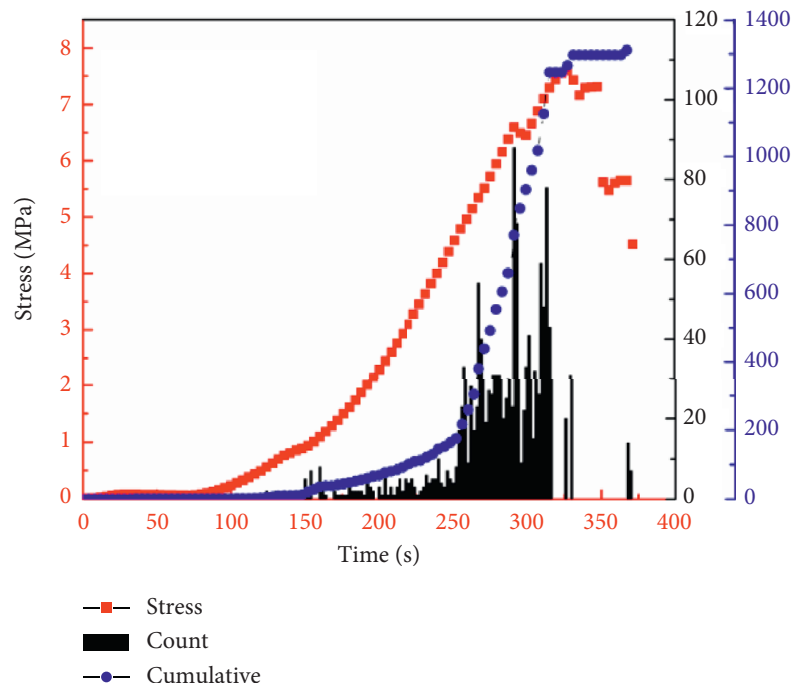

(c)

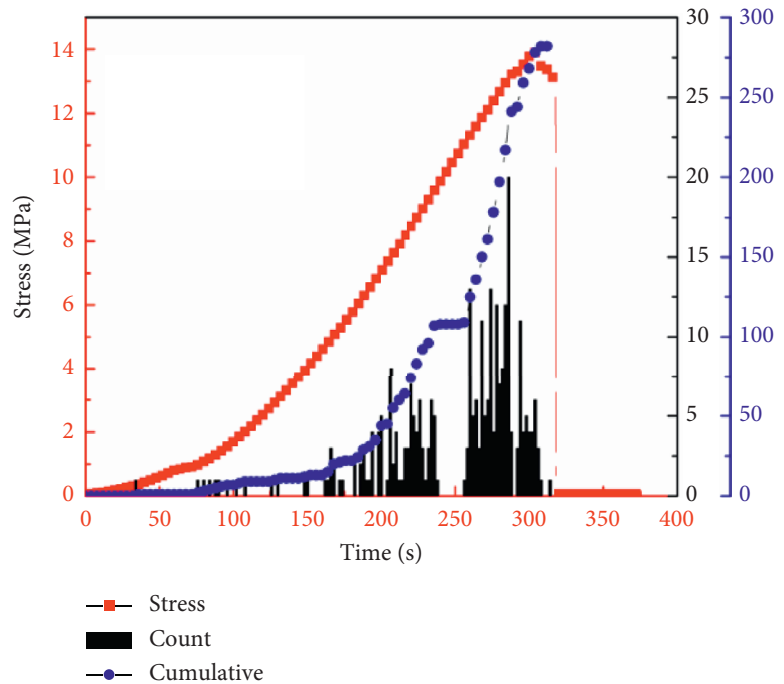

(d)

Figure 12: Relationship between AE event, stress, and time ("count" represents AE event count and "cumulative" represents AE cumulative event count). (a) Coal sample no. 0. (b) Coal sample no. 2. (c) Coal sample no. 4. (d) Coal sample no. 5.

coal samples and taking the axial stresses of raw coal samples in the loading process of $60 \%, 95 \%$, and $100 \%$ of the maximum compressive strength as nodes, the stress state of raw coal samples is divided into four stages. They are elastic stage (0 60\%), yield stage (60\% 95\%), plastic stage (95\% $100 \%$ ), and postpeak stage, respectively. The AE events and their amplitude characteristics in different stages are statistically analyzed, as shown in Figure 13.

The numbers 1, 2, 3, and 4 on the color bars in Figure 12 represent the elastic stage (0 60\%), yield stage (60\% 95\%), plastic stage (95\% 100\%), and postpeak stage, respectively. Four spheres with different diameters represent the energy amplitudes of different $\mathrm{AE}$ events. According to the final statistics, the numbers of $\mathrm{AE}$ events in the elastic stage of the four raw coal samples are $401,324,120$, and 64 , and the average energy amplitudes are 69.28, 63.58, 64.82, and 66.52 , respectively. The AE events in the yield stage are 705 , 166,1046 , and 177, and the average energy amplitudes are $54.43,63.84,64.45$, and 66.51, respectively. The AE events in the plastic stage are $136,1,63$, and 31 , with averages of $69.28,63.58,64.82$, and 66.52 , respectively. The energy amplitudes were 69.54, 86, 64.21, and 69.94, respectively. The number of AE events in postpeak stage was $125,16,39$, and 11 , and the average energy amplitude was $67.68,72.13$, 64.64 , and 73.10, respectively. It can be seen from Figure 13 that the $\mathrm{AE}$ events are mainly concentrated in the elastic stage and yield stage. At these stages, the original fracture experienced the process of compaction and then opening. However, in the plastic stage, the number of AE events is small, while the energy amplitude is large. This is due to the formation of new fractures and the increase of $\mathrm{AE}$ event energy amplitude. It is concluded that the AE events have a good positioning function which can accurately locate the specific location of $\mathrm{AE}$ events and better reflect the evolution law of internal cracks in raw coal samples during uniaxial compression.

\section{Discussion}

The existing research results show that the occurrence of coal and gas outburst and rockburst has a high degree of suddenness [23-25]. Therefore, the coal-gas outburst and rockburst could be predicted and prevented. In fact, most of the coal and gas outburst and rockburst accidents present certain precursory characteristics before they occur, such as the sound of coal burst, spalling, and coal body displacement. Predecessors have done a lot of research in this field. Similarly, the occurrence of coal-gas compound dynamic disaster is also induced by the instability of coal and rock. As for coal-gas compound dynamic disaster, before the failure of coal and rock, it will still release and produce a large number of AE signals, which has important practical significance for the study of the AE evolution law in the process of coal and rock damage. In this work, we obtained the AE response characteristics of anthracitic coal under uniaxial compression and focused on the similarities and differences of the ring count, energy count, and $\mathrm{AE}$ events with time in uniaxial compression process. All these three AE parameters with time during uniaxial compression are approximate to normal distributions and they all could slightly reflect the evolution process of cracks in coal-rock fracture process. However, through the location study of $\mathrm{AE}$ events, it is found that $\mathrm{AE}$ events have a good positioning function which can accurately locate the specific location of AE events and better reflect the evolution law of internal cracks in raw coal samples during uniaxial compression. Therefore, in the engineering practice of the prevention of coal-gas compound dynamic disaster, the AE events can be used as one of the main AE characteristic parameters. The results of spatial location of $\mathrm{AE}$ events in front of the working face could be used to predict the fracture and instability of coal and rock, which is also conducive to the prediction of coal-gas compound dynamic disaster and improve the accuracy of its 


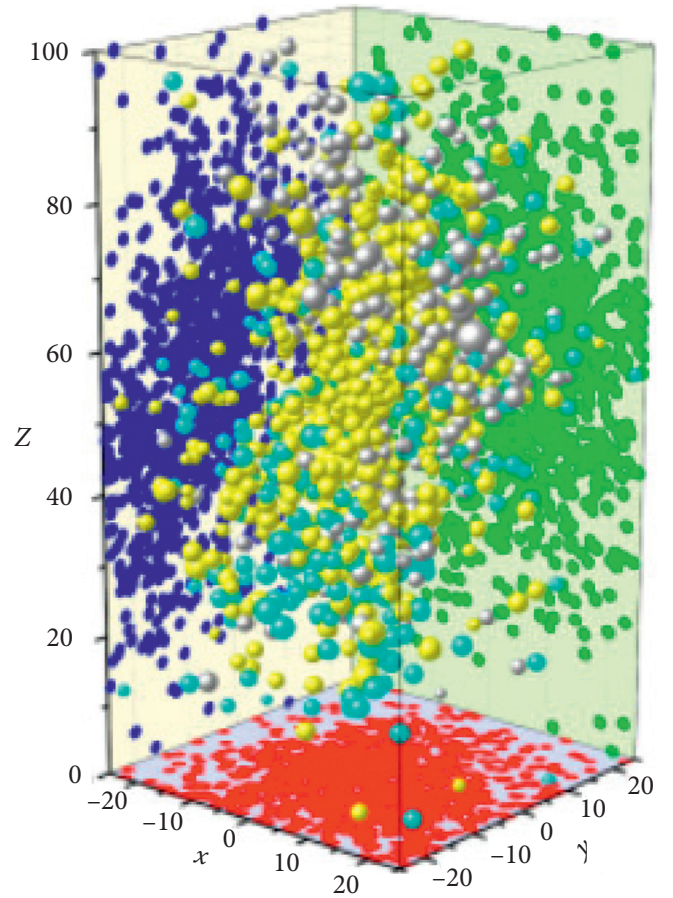

(a)

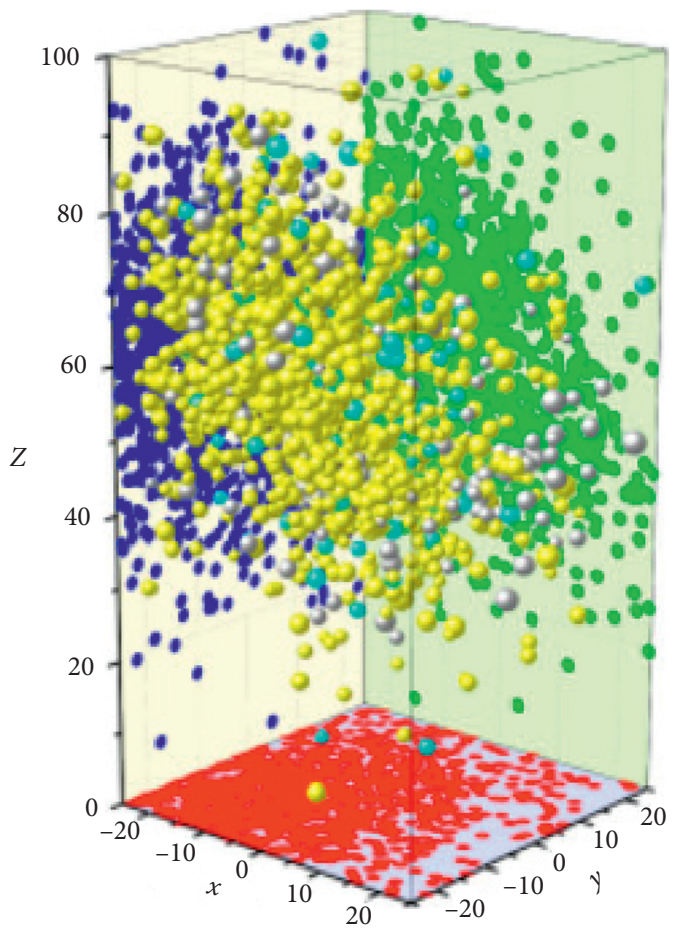

(c)
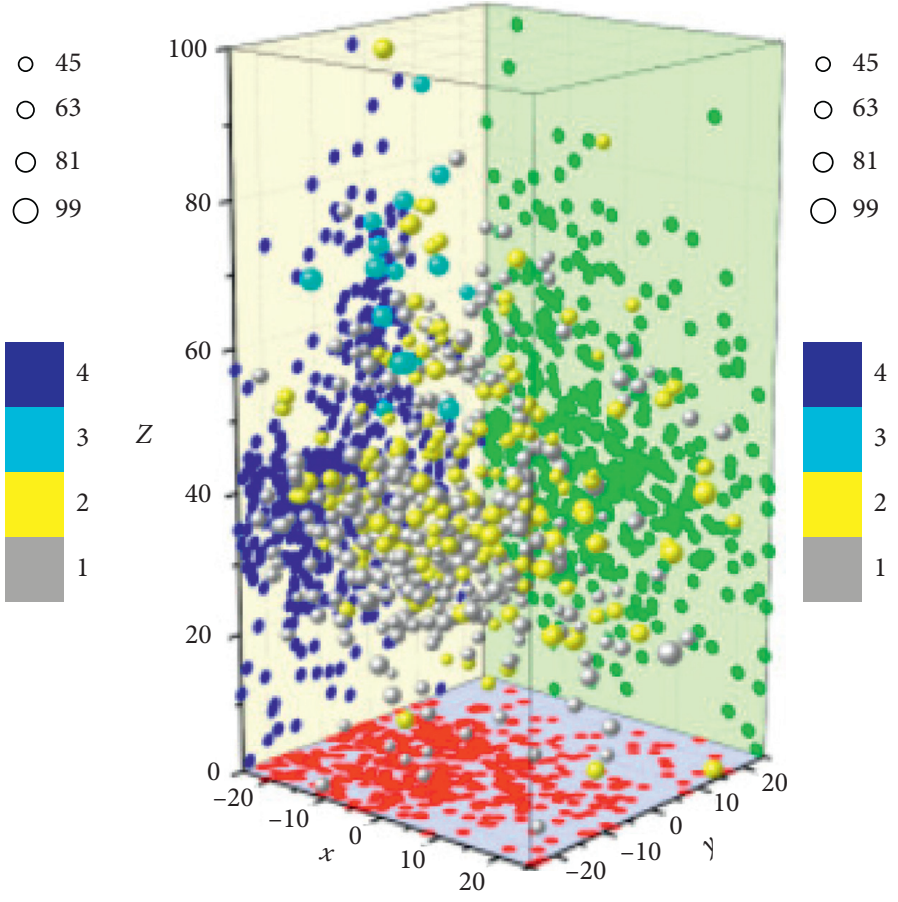

(b)
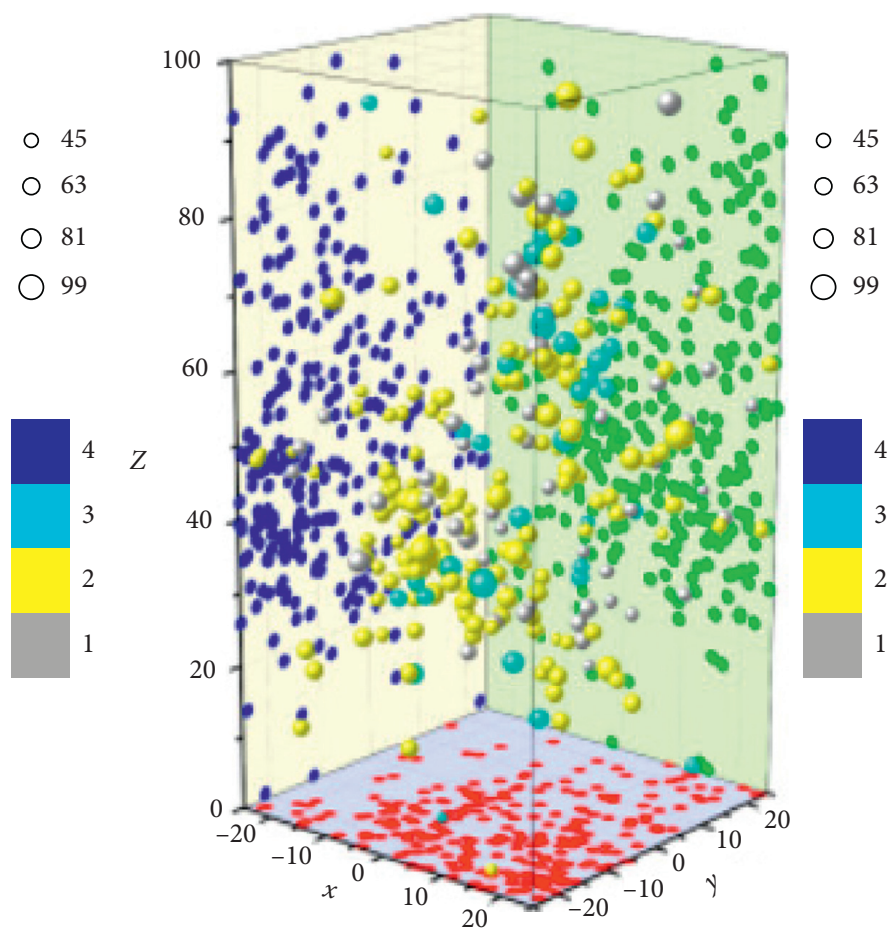

(d)

FIgURE 13: AE source three-dimensional positioning. (a) Coal sample no. 0. (b) Coal sample no. 2. (c) Coal sample no. 4. (d) Coal sample no. 5.

prediction. The preliminary study of this work is supposed to suggest researchers to study in depth the mechanism of coalgas compound dynamic disaster using AE technology.

The research in this work also shows that although the selected raw coal samples are taken from the same block coal, the mechanical properties are still different. As a result, the
AE signal may jump and have large dispersion. The enlightenment to us is that the prediction of coal-gas compound dynamic disaster by using AE characteristics of coal should also be based on long-term monitoring. In this work, the characteristics of $\mathrm{AE}$ of coal and rock in the process of coal-gas compound dynamic disaster are only carried out in 
the laboratory scale, and the field scale test has not been designed. In the future, more in-depth researches on the mechanism of coal-gas compound dynamic disaster based on AE technology are needed. Moreover, the continuous scale field monitoring of AE signal in the process of coal-gas compound dynamic disaster is the focus of our future research.

\section{Conclusions}

(1) For the same raw coal sample, there are some differences in the wave velocities in three directions, which indicates that the raw coal sample has certain nonuniformity and anisotropy.

(2) The ring count, energy count, and AE events with time in uniaxial compression process are approximate to normal distribution, and these three parameters are close to the variation law of axial stress of coal during uniaxial compression. Through the change characteristics of these three parameters, the formation, development, and expansion characteristics of internal cracks in raw coal samples can be obtained.

(3) The AE events are concentrated in the elastic stage and yield stage, and the energy amplitude of $\mathrm{AE}$ events is higher in the plastic stage. Compared with ring count and energy count, $\mathrm{AE}$ events have a good positioning function, which can better reflect the evolution of internal cracks of raw coal samples during uniaxial compression.

\section{Data Availability}

The data used to support the findings of this study are available from the corresponding author upon request.

\section{Conflicts of Interest}

The authors declare that they have no conflicts of interest.

\section{Acknowledgments}

This research was funded by the Science and Technology Innovation Project of China Energy Investment Corporation (SHJT-16-24), the National Natural Science Foundation of China (51804161, 51774291, and 51864045), the Joint Fund Project of Bijie Science and Technology (G[2019]6), the Youth Science and Technology Talent Growth Fund of Guizhou Education Department (KY[2019]154), and the Guizhou Science and Technology Support Program ([2017] 2820).

\section{References}

[1] C. Fan, S. Li, D. Elsworth, J. Han, and Z. Yang, "Experimental investigation on dynamic strength and energy dissipation characteristics of gas outburst-prone coal," Energy Science \& Engineering, vol. 8, no. 4, pp. 1015-1028, 2020.

[2] Y. Cheng, H. Jiang, X. Zhang, J. Cui, C. Song, and X. Li, "Effects of coal rank on physicochemical properties of coal and on methane adsorption," International Journal of Coal Science \& Technology, vol. 4, no. 2, pp. 129-146, 2017.

[3] H. Xie, Y. Ju, F. Gao, M. Gao, and R. Zhang, "Groundbreaking theoretical and technical conceptualization of fluidized mining of deep underground solid mineral resources," Tunnelling and Underground Space Technology, vol. 67, pp. 68-70, 2017.

[4] B. Zhao, G. Wen, H. Sun et al., "Similarity criteria and coallike material in coal and gas outburst physical simulation," International Journal of Coal Science \& Technology, vol. 5, no. 2, pp. 167-178, 2018.

[5] F. Du, K. Wang, G. Wang, Y. Jiang, C. Xin, and X. Zhang, "Investigation of the acoustic emission characteristics during deformation and failure of gas-bearing coal-rock combined bodies," Journal of Loss Prevention in the Process Industries, vol. 55, pp. 253-266, 2018.

[6] F. Du and K. Wang, "Unstable failure of gas-bearing coal-rock combination bodies: insights from physical experiments and numerical simulations," Process Safety and Environmental Protection, vol. 129, pp. 264-279, 2019.

[7] Y. Pan, "Integrated study on compound dynamic disaster of coal-gas outburstand rockburst," Journal of China Coal Society, vol. 41, pp. 105-112, 2016.

[8] Y. Liu and Y. Zhu, "Comparison of pore characteristics in the coal and shale reservoirs of Taiyuan formation, Qinshui basin, China," International Journal of Coal Science \& Technology, vol. 3, no. 3, pp. 330-338, 2016.

[9] A. Liu, S. Liu, G. Wang, and G. Sang, "Modeling of coal matrix apparent strains for sorbing gases using a transversely isotropic approach," Rock Mechanics and Rock Engineering, vol. 53, no. 9, p. 4163, 2020.

[10] A. Carpinteri, G. Lacidogna, F. Accornero, A. C. Mpalaskas, T. E. Matikas, and D. G. Aggelis, "Influence of damage in the acoustic emission parameters," Cement and Concrete Composites, vol. 44, no. 44, pp. 9-16, 2013.

[11] A. Carpinteri, M. Corrado, and G. Lacidogna, "Heterogeneous materials in compression: correlations between absorbed, released and acoustic emission energies," Engineering Failure Analysis, vol. 33, no. 7, pp. 236-250, 2013.

[12] R. Yuan and B. Shi, "Acoustic emission activity in directly tensile test on marble specimens and its tensile damage constitutive model," International Journal of Coal Science \& Technology, vol. 5, no. 3, pp. 295-304, 2018.

[13] V. L. Shkuratnik, Y. L. Filimonov, and S. V. Kuchurin, "Experimental investigations into acoustic emission in coal samples under uniaxial loading," Journal of Mining Science, vol. 40, no. 5, pp. 458-464, 2004.

[14] M. Seto, H. Sato, M. Sato, and M. Kohno, "Hypocenter distributions of ae in coal under uniaxial compression," Journal of the Mining Institute of Japan, vol. 104, no. 1201, pp. 163-168, 1988.

[15] V. Vishal, P. G. Ranjith, and T. N. Singh, "An experimental investigation on behaviour of coal under fluid saturation, using acoustic emission," Journal of Natural Gas Science and Engineering, vol. 22, pp. 428-436, 2015.

[16] X. Kong, E. Wang, S. Hu et al., "Critical slowing down on acoustic emission characteristics of coal containing methane," Journal of Natural Gas Science and Engineering, vol. 24, pp. 156-165, 2015.

[17] X. Kong, E. Wang, S. Hu, R. Shen, X. Li, and T. Zhan, "Fractal characteristics and acoustic emission of coal containing methane in triaxial compression failure," Journal of Applied Geophysics, vol. 124, pp. 139-147, 2016.

[18] X. Kong, E. Wang, X. He, D. Li, and Q. Liu, "Time-varying multifractal of acoustic emission about coal samples subjected 
to uniaxial compression," Chaos, Solitons \& Fractals, vol. 103, pp. 571-577, 2017.

[19] C. Jiang, M. Duan, G. Yin et al., "Experimental study on seepage properties, ae characteristics and energy dissipation of coal under tiered cyclic loading," Engineering Geology, vol. 221, pp. 114-123, 2017.

[20] H. Song, Y. Zhao, D. Elsworth, Y. Jiang, and J. Wang, "Anisotropy of acoustic emission in coal under the uniaxial loading condition," Chaos, Solitons \& Fractals, vol. 130, Article ID 109465, 2020.

[21] G. Z. Sun, Structural Mechanics of Rock Mass, Science Press, Beijing, China, 1998.

[22] X. Zhang, "Study of relationship between Poisson's ratio and angle of internal friction for rocks," Chinese Journal of Rock Mechanics and Engineering, vol. 30, no. S1, pp. 2599-2609, 2011.

[23] P. Konicek, K. Soucek, L. Stas, and R. Singh, "Long-hole destress blasting for rockburst control during deep underground coal mining," International Journal of Rock Mechanics and Mining Sciences, vol. 61, pp. 141-153, 2013.

[24] R. D. Lama and J. Bodziony, "Management of outburst in underground coal mines," International Journal of Coal Geology, vol. 35, no. 1-4, pp. 83-115, 1998.

[25] B. María, C. Díaz Aguado, and N. González, "Control and prevention of gasoutbursts in coal mines, Riosa-Olloniego coalfield, Spain," International Journal of Coal Geology, vol. 69, no. 4, pp. 253-266, 2007. 